\title{
Advanced Treatment for Basal Cell Carcinomas
}

\author{
Scott X. Atwood, Ramon J. Whitson, and Anthony E. Oro \\ Program in Epithelial Biology, Stanford University School of Medicine, Stanford, California 94305 \\ Correspondence: oro@stanford.edu
}

Basal cell carcinomas (BCCs) are very common epithelial cancers that depend on the Hedgehog pathway for tumor growth. Traditional therapies such as surgical excision are effective for most patients with sporadic BCC; however, better treatment options are needed for cosmetically sensitive or advanced and metastatic BCC. The first approved Hedgehog antagonist targeting the membrane receptor Smoothened, vismodegib, shows remarkable effectiveness on both syndromic and nonsyndromic BCCs. However, drug-resistant tumors frequently develop, illustrating the need for the development of next-generation Hedgehog antagonists targeting pathway components downstream from Smoothened. In this article, we will summarize available BCC treatment options and discuss the development of next-generation antagonists.

$\mathrm{B}^{\mathrm{a}}$ asal cell carcinomas (BCCs) are locally invasive epithelial tumors that arise from activating mutations in the Hedgehog $(\mathrm{HH})$ signaling pathway (Rubin et al. 2005). HH-dependent cancers emanate from many organs such as brain, pancreas, prostate, bladder, and lung, accounting for up to $25 \%$ of all human cancer deaths (Epstein 2008). As BCCs are readily visible and rarely metastasize, surgical excision is the most common therapy. However, surgery is less effective in patients with multiple tumors, tumors in cosmetically sensitive areas, and late-stage or metastatic cancer, indicating a need for additional alternative therapies. After $20 \mathrm{yr}$ of research into the identity and functional roles of $\mathrm{HH}$ pathway components, the Food and Drug Administration (FDA) recently approved vismodegib (Erivedge; Genentech/Roche) as a first-generation $\mathrm{HH}$ pathway antagonist for the treatment of late-advanced or metastatic BCC.
Vismodegib is an effective therapy that shrinks tumors to a manageable size; however, as with most cancer drugs, some tumors evolve and acquire resistance over time. How these tumor cell populations adapt to circumvent $\mathrm{HH}$ pathway blockade is an active area of investigation that is leading to the discovery of next-generation therapeutic targets for treating $\mathrm{HH}$-dependent cancers. In this review, we will discuss the traditional therapies to treat BCCs, first generation of $\mathrm{HH}$ pathway antagonists, and how research into drug-resistant mechanisms are leading to the development of the next generation of therapeutics for $\mathrm{HH}$-dependent cancers.

\section{HEDGEHOG: AN ESSENTIAL LINK TO BCC}

Inappropriate activation of the $\mathrm{HH}$-signaling pathway drives tumor growth from many areas of the human body and is responsible for all

Editors: Anthony E. Oro and Fiona M. Watt

Additional Perspectives on The Skin and Its Diseases available at www.perspectivesinmedicine.org

Copyright (C) 2014 Cold Spring Harbor Laboratory Press; all rights reserved; doi: 10.1101/cshperspect.a013581

Cite this article as Cold Spring Harb Perspect Med 2014;4:a013581 
S.X. Atwood et al.

known BCC cases (Varjosalo and Taipale 2008). The HH pathway derives its name from its ligand, of which there are three mammalian homologs: Sonic Hedgehog (SHH), Indian Hedgehog, and Desert Hedgehog. SHH is the ligand that predominantly operates in the skin (Fig. 1). In the absence of $\mathrm{HH}$ ligand, transmembrane receptor Patched1 (PTCH1) suppresses the seven-pass transmembrane protein Smoothened (SMO) and Suppressor of Fused (SUFU) inhibits glioma-associated oncogene (GLI) transcription factors that control $\mathrm{HH}$ pathway response. Any $\mathrm{HH}$ isoform will bind to and inhibit PTCH1, allowing SMO to become active and suppress SUFU, causing activation of GLI by mechanisms that are still unclear. GLI amplifies $\mathrm{HH}$ target gene expression with GLI1 serving mainly as an activator, GLI3 mainly as a repressor, and GLI2 capable of either function. Mutations that inappropriately activate $S H H$, inhibit PTCH1, or activate SMO comprise nearly all of known BCC cases (Epstein 2008; GomezOspina et al. 2012). Combined with evidence that shows $\mathrm{HH}$ target gene induction in human skin grafts results in BCC-like changes (Callahan et al. 2004), aberrant $\mathrm{HH}$ pathway activation is sufficient for tumorigenesis.

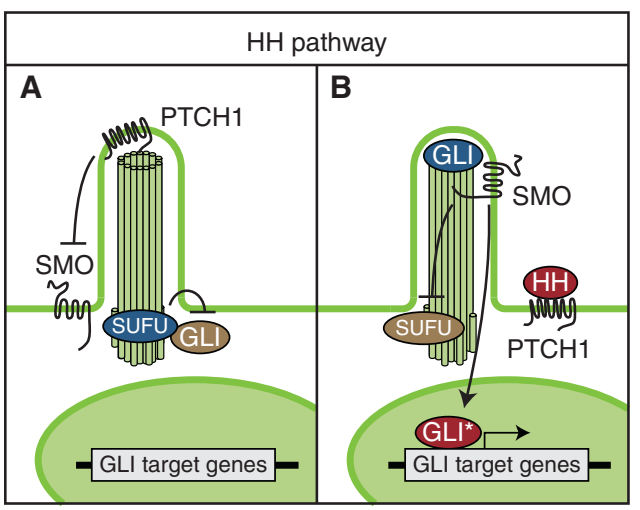

Figure 1. HH pathway activation. (A) In the absence of HH ligand, ciliary PTCH1 inhibits SMO activity and ciliary localization. SUFU prevents GLI nuclear localization and target gene induction. (B) $\mathrm{HH}$ ligand binds and induces PTCH1 translocation from the cilia, allowing active SMO to enter the cilia and suppress SUFU function, allowing active GLI to enter the nucleus and induce target genes.
A surprising aspect of the mammalian $\mathrm{HH}$ pathway stems from its requirement for an organelle called the primary cilium, a microtubule-based structure derived from the mother centriole during interphase (Huangfu et al. 2003). Primary cilia are found on most cells in the human body and process signals from several signaling pathways, although the $\mathrm{HH}$ pathway is the most well known and studied. Abnormalities in cilia and ciliary components give rise to a variety of developmental defects, or ciliopathies, and cancer (Hildebrandt et al. 2011; Hui and Angers 2011). HH pathway components localize and are processed by the primary cilium, priming the pathway to accept and amplify HH signal (Hui and Angers 2011). In the absence of HH ligand, PTCH1 sits in the cilium and suppresses SMO activity and localization. $\mathrm{HH}$ ligand binds $\mathrm{PTCH} 1$ and promotes its exit from the cilium, allowing SMO and GLI to enter the cilium where GLI is processed to its active form for transport to the nucleus to turn on $\mathrm{HH}$ target genes (Humke et al. 2010; Tukachinsky et al. 2010). Mutations that disrupt intraflagellar transport (IFT), the mechanism the cilium uses to move cargo into and out of the organelle, inappropriately accumulate or lose $\mathrm{HH}$ components in the cilium and result in defective $\mathrm{HH}$ signal transduction (Keady et al. 2012). In addition, IFT mutations in Ift88 or Kif3a suppress primary cilia formation and can either promote or inhibit BCC proliferation, potentially limiting their effectiveness as a therapeutic target (Wong et al. 2009). Ift88 or Kif3a mutations can inhibit $\mathrm{HH}$ pathway activation and BCC arising from activating SMO mutations by blocking GLI processing to its active form, or accelerate tumors induced by activating GLI mutations by blocking GLI repressor formation.

\section{TRADITIONAL THERAPEUTICS FOR BCC}

BCCs originate from basal progenitors of the interfollicular epidermis and hair follicle (Epstein 2011). In mice, activation of the HH pathway by conditional loss of Ptch1 in the interfollicular epidermis, follicular bulge, or secondary hair germ leads to tumor formation (Wang et al. 2011). In contrast, overexpression of a constitu- 
tively active Smo mutation (SmoM2) induces tumor formation only in the interfollicular epidermis (Youssef et al. 2010). However, wounding can promote tumor formation from the follicular bulge-expressing SmoM2, in which progenitor cells from the bulge invade the wound site causing tumors in rare instances (Kasper et al. 2011; Wong and Reiter 2011). Alternatively, expression of a constitutively active Gli2 mutation $(\mathrm{Gli} 2 \Delta \mathrm{N})$ can promote tumors in the epidermis, sebaceous gland, follicular bulge, and secondary hair germ (Grachtchouk et al. 2011). These studies reinforce the idea that BCC can arise from cells competent to receive $\mathrm{HH}$ signal and activate GLI transcription factors and target genes (Oro et al. 1997; Nilsson et al. 2000; Oro and Higgins 2003).

BCC typically arises from body areas exposed to sunlight with $80 \%$ of cases on the head and neck (Rubin et al. 2005). Ultraviolet light, smoking, and ionizing radiation are among the risk factors that can cause driver mutations in the $\mathrm{HH}$ pathway, with light-haired and fairskinned individuals particularly sensitive. BCCs retain basal keratinocyte histology, invade as either branching or nest-like structures, and typically are superficial with scaly patches or nodular with pearly nodules that can be crusty or ulcerative. Metastasis is rare with $<1 \%$ of cases progressing to this stage with a median time of $8 \mathrm{yr}$ after the initial lesion forms.

Local surgical excision and chemotherapy are the most common traditional therapies to treat BCC (Rubin et al. 2005). Surgical methods include curettage (scooping or scraping), electrodissection (burning), cryosurgery (freezing), surgical excision, and Mohs surgery (progressive excision with real-time pathology). Curettage, electrodissection, and cryosurgery are typically used for superficial and nodular BCC, but are inappropriate for recurrent or metastatic BCC. Nonsurgical methods include radiotherapy (radiation), topical or injectable chemotherapy, and photodynamic therapy. Radiotherapy is used for nonsurgical candidates or difficult tumor locations and is avoided in patients younger than $60 \mathrm{yr}$ of age. Photodynamic therapy involves administering a tumoricidal photosensitizing agent that localizes to the tumor and is locally activated by visible light. Although effective in superficial and nodular tumors, recurrence can limit the effectiveness of this procedure. Traditional therapies are effective for superficial and nodular BCC; however, they are less effective for patients with multiple tumors, late advanced or metastatic tumors, and BCC lesions occurring in cosmetically sensitive areas.

\section{TARGETING SMO, FIRST-GENERATION HH ANTAGONISTS}

The idea of targeting the HH pathway for treating HH-dependent cancers came from scientists who observed that a plant ingested by sheep induced birth defects similar to those in $\mathrm{SHH}$ mice. Cyclopamine is a plant alkaloid and one of the active ingredients in Veratrum californicum, which was found to induce cyclopia in offspring when fed to pregnant sheep (Keeler and Binns 1966). As cyclopia is one of the defects in mice lacking $\mathrm{SHH}$ (Chiang et al. 1996), this phenotype provided an important connection between cyclopamine and $\mathrm{HH}$ pathway activation. Cyclopamine was later purified and shown to potently inhibit SMO (Chen et al. 2002). This connection invigorated scientists to identify additional SMO antagonists using in vitro screens to sift through thousands of compounds. Subsequent work by several independent groups led to the discovery of a number of SMO antagonists, including vismodegib (trade name Erivedge) as the first FDA-approved SMO inhibitor for late advanced and metastatic BCC (Robarge et al. 2009).

Vismodegib is quite effective at suppressing BCC tumor growth and appears both tumoricidal and tumoristatic (Sekulic et al. 2012; Tang et al. 2012). Many tumors regrew after cessation of the drug, suggesting the most efficient use of vismodegib as a therapeutic is to shrink tumors to a manageable level and surgically excise any remaining tumor clones. Side effects during treatment were mild to moderate and included muscle spasms, alopecia, taste loss, weight loss, fatigue, nausea, decreased appetite, and diarrhea. Most, if not all, side effects ceased after patients stopped taking the drug. A host of SMO inhibitors are currently in development 
S.X. Atwood et al.

that may be used to treat BCC in the near future (Table 1). The large number of clinical trials underway exploring the use of SMO inhibitors in treating $\mathrm{HH}$-dependent cancers underscores the intense interest in this class of $\mathrm{HH}$ antagonists. Currently, SMO inhibitors that are in phase I or II clinical trials to treat advanced or metastatic BCC include erismodegib (NVPLDE225), XL-139, LEQ506, and BMS-833923 (Tang and Marghoob 2011).

Recent clinical trials showed heterogeneous responses to vismodegib that depended on the patient group being treated. The most sensitive patient population were basal cell nevus syndrome (BCNS) patients who carry a PTCH1 mutation that predisposes them to developing hundreds of BCCs. BCNS patients treated with vismodegib showed a 100\% (38 of 38) response rate (Tang et al. 2012). Despite many tumors on each patient, none of these tumors acquired resistance during treatment, as is common with many other cancer drugs. In contrast, in sporadic cases only half of patients (19 out of 33) in phase I clinical trials with late advanced or metastatic BCC showed tumor regression with vismodegib treatment despite having a similar histology to BCNS patients (Hoff et al. 2009; LoRusso et al. 2011). In phase II clinical trials, only $30 \%$ (10 of 33 ) of metastatic and $43 \%$ (27 of 63) late advanced BCC patients responded to vismodegib (Sekulic et al. 2012). In addition, other $\mathrm{HH}$-driven tumors such as pancreatic or small cell lung cancers showed little to no response to vismodegib despite inhibition of the $\mathrm{HH}$ pathway (LoRusso et al. 2011). These results suggest slower evolving tumors with low mutation rates such as sporadic BCC or BCNS patients will respond well to SMO inhibition, whereas metastatic BCC with higher mutational rates have a higher likelihood of acquired resistance before or during drug treatment. In fact, the rate of acquired resistance in advanced tumor-bearing patients that initially responded to vismodegib is $21 \%$ ( 6 out of 28 ) with mean time to tumor regrowth at $56 \mathrm{wk}$ (Chang and Oro 2012). Taken together, these results indicate a need to understand tumor evolution to develop $\mathrm{HH}$ antagonists that target patients who do not initially respond to vismodegib or acquire resistance over the course of treatment.

Table 1. HH pathway antagonists that are in current use, development, or have potential clinical use for treatment of BCCs

\begin{tabular}{llll}
\hline Inhibitor & Target & Stage of development & \multicolumn{1}{c}{ Reference } \\
\hline Vismodegib & SMO & In clinical use & Sekulic et al. 2012 \\
PF-04449913 & SMO & Phase I & Munchhof et al. 2012 \\
Erismodegib & SMO & Phase II & Skvara et al. 2011 \\
LEQ506 & SMO & Phase I & Lappano and Maggiolini 2011 \\
BMS-833923 & SMO & Phase I & Bristol-Myers Squibb 2013 \\
Saridegib & SMO & Phase II & Tremblay et al. 2009 \\
Itraconazole & SMO & Phase I & Kim et al. 2013 \\
CUR61414 & SMO & Preclinical & Tang et al. 2011 \\
ALLO-1 and 2 & SMO & Preclinical & Tao et al. 2011 \\
Robotnikinin & SHH & Preclinical & Hassounah et al. 2012 \\
5E1 & SHH & Preclinical & Maun et al. 2010 \\
ATO & GLI & Phase I & Kim et al. 2013 \\
GANT-61 & GLI? & Preclinical & Lauth et al. 2007 \\
GANT-58 & GLI? & Preclinical & Lauth et al. 2007 \\
HPI-1 through -4 & GLI? & Preclinical & Hyman et al. 2009 \\
Sirolimus & mTOR & Phase I & Campbell et al. 2012 \\
PF-4708671 & S6K1 & Preclinical & Pearce et al. 2010 \\
PSI & aPKC & Preclinical & Atwood et al. 2013 \\
\hline
\end{tabular}

SMO, Smoothened; SHH, Sonic Hedgehog; ATO, arsenic trioxide; mTOR, mammalian target of rapamycin; S6K1, S6 kinase 1 ; aPKC, atypical protein kinase $\mathrm{C} \iota / \lambda$. 


\section{EVOLVING DRUG RESISTANCE}

How do tumors bypass SMO inhibition? In general, tumors are heterogeneous with multiple clones occupying the same lesion. Over the course of treatment, drug-resistant clones that are initially present in low numbers can become dominant as they gain a growth advantage as sensitive clones die off (Fig. 2) (Diaz et al. 2012; Misale et al. 2012). This suggests initially targeting multiple pathways may be more effective than targeting any single pathway. Understanding how tumors evolve resistance can direct this "personalized" medicine whereby prescreening patients before starting therapy may drive the next generation of cancer treatments. Although little information is known about resistant mechanisms in BCC, examining how other $\mathrm{HH}$-driven cancers evolve resistance suggests BCCs can bypass SMO inhibition through $\mathrm{HH}$-specific genetic alterations or compensatory adaptation (Atwood et al. 2012).

Several $\mathrm{HH}$-specific genetic alterations were discovered in mice and humans harboring SMO inhibitor-resistant medulloblastoma, an $\mathrm{HH}-$ driven brain cancer (Fig. 3). These studies suggest genetic alterations at or downstream from SMO can promote resistance to SMO antago-

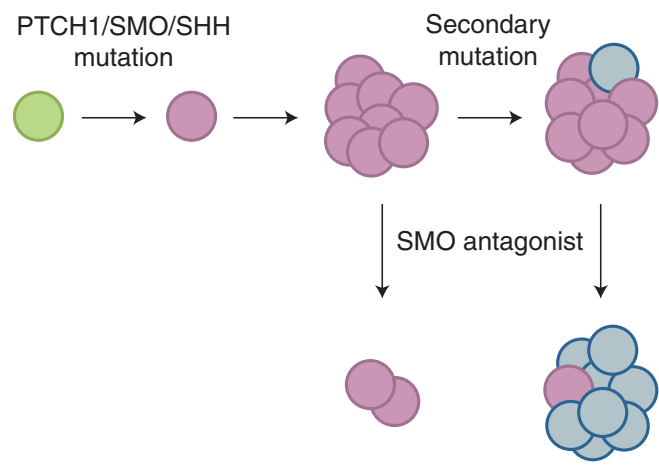

Figure 2. Model of tumor heterogeneity. A normal cell (green) can convert to a tumor cell (purple) by acquiring an $\mathrm{HH}$ pathway mutation. As the tumor cell divides, clonal populations (blue) can gain secondary mutations that promote drug resistance. When SMO antagonist is applied, tumors with no resistant clones will shrink, whereas tumors with resistant clones will continue to grow.

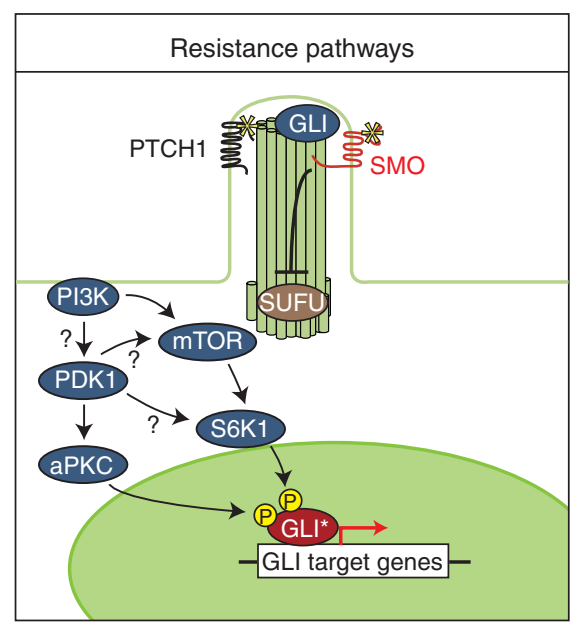

Figure 3. Resistance pathways in HH-dependent cancers. One of the most common resistance pathways is Smo mutation in the ligand binding pocket or the carboxyl terminus. Activation of GLI downstream from SMO also appears to be a frequent resistance pathway that can bypass SMO inhibition. GLI is directly activated by atypical protein kinase $\mathrm{C} \iota / \lambda$ (aPKC), which requires activation by PDK1. S6 kinase 1 (S6K1) prevents SUFU inhibition of GLI, and is activated by the phosphoinositide 3-kinase $(\mathrm{PI} 3 \mathrm{~K}) /$ mammalian target of rapamycin (mTOR) pathway. PI3K can promote PDK1 activation and PDK1 can promote mTOR and S6K1 activation, but whether these molecular events can cause resistance in $\mathrm{HH}$-dependent cancers remains to be determined. PI3K can also promote resistance in a GLIindependent manner.

nist therapy. Multiple point mutations throughout SMO can block drug interaction while maintaining high levels of SMO activity (Yauch et al. 2009; Buonamici et al. 2010; Dijkgraaf et al. 2011). These mutations occur in the ligandbinding pocket of SMO and areas thought to transduce SMO signal. Other genetic alterations that drive tumor resistance are independent of SMO and include genetic amplification of select $\mathrm{HH}$ target genes. Gene duplications of CCND1 or GLI2 have been shown to inappropriately maintain pathway activation even in the presence of SMO inhibitors in mouse models of medulloblastoma (Buonamici et al. 2010; Dijkgraaf et al. 2011).

Compensatory alterations, transient events in which $\mathrm{HH}$ activation occurs in the absence of 
S.X. Atwood et al.

genetic alterations in $\mathrm{HH}$ pathway genes, have also been observed to mediate $\mathrm{HH}$-driven tumor resistance. Despite originating outside of canonical $\mathrm{HH}$ pathway genes, compensatory alterations drive high levels of $\mathrm{HH}$ activation downstream from SMO. These alterations include up-regulation of the PI3K pathway (Buonamici et al. 2010). PI3K and its downstream effectors were up-regulated in mouse models of medulloblastoma harboring SMO-resistant tumors. PI3K pathway members were enriched in resistant tumors at the transcript level over sensitive tumors suggesting PI3K signaling can maintain $\mathrm{HH}$ pathway activation. PI3K signaling can promote GLI-dependent transcription in a cellular environment with low levels of $\mathrm{HH}$ ligand (Riobó et al. 2006), suggesting that PI3K signaling may influence the $\mathrm{HH}$ pathway most effectively when in the presence of Smo antagonists.

How PI3K promotes $\mathrm{HH}$ signaling is unclear, although two components that often act downstream from PI3K, S6K1 and aPKC, also show elevated levels in resistant tumors and are reported to promote GLI-dependent transcription. mTOR pathway component S6K1 was found to be elevated in esophageal cancers resistant to SMO antagonists (Wang et al. 2012). S6K1 promotes GLI-dependent transcription by phosphorylating GLI1, which prevents an inhibitory interaction with SUFU that allows GLI to enter into the nucleus and turn on target genes. S6K1 is also inappropriately activated in some medulloblastomas (Dijkgraaf et al. 2011), suggesting this may be a general resistance mechanism of HH-dependent cancers. Similarly, aPKC has been shown to be overly active in vismodegib-resistant BCC (Atwood et al. 2013). aPKC is an $\mathrm{HH}$ target gene that phosphorylates GLI1 at distinct sites from S6K1, activating GLI1 DNA binding and transcriptional activity to generate a positive-feedback loop that amplifies GLI-dependent transcription in BCC.

\section{DEVELOPING THE NEXT GENERATION OF HH ANTAGONISTS}

There is phenomenal interest in developing the next generation of $\mathrm{HH}$ antagonists given the current knowledge of escape pathways $\mathrm{HH}$ driven tumors use to bypass SMO blockade. Developing a pantry of effective targeted therapies and prescreening tumors for specific resistant biomarkers will allow physicians to better treat their patients and curb tumor resistance. Next-generation $\mathrm{HH}$ antagonists are currently in preclinical testing or early phase clinical trials that target known escape pathways and include mutant SMO, SHH, GLI, mTOR, S6K1, and aPKC.

The first set of next-generation $\mathrm{HH}$ antagonists target drug-resistant SMO. D473H (D477G in mouse) is an acquired mutation in medulloblastoma that prevents vismodegib from binding SMO effectively (Yauch et al. 2009). In an attempt to find a SMO antagonist that works in the presence of $\mathrm{D} 473 \mathrm{H}$, one group screened through 50,000 compounds for small molecules that inhibit $\mathrm{HH}$ pathway activation in the presence of $\mathrm{HH}-\mathrm{Ag} 1.5$, a HH agonist that competes with vismodegib and 3-keto- $\mathrm{N}$-(aminoethyl-aminocaproyl-dihydrocinnamoyl)-cyclopamine (Tao et al. 2011). Two compounds, ALLO-1 and ALLO-2, were able to inhibit Gliluciferase expression in TM3-Gli-Luc mouse cells regardless of $\mathrm{HH}-\mathrm{Ag} 1.5$ concentration. ALLO-1 competes with BODIPY-cyclopamine (a fluorescent derivative of cyclopamoine), whereas ALLO-2 competes with both cyclopamine and BODIPY-cyclopamine, suggesting that these compounds act separately from vismodegib and on distinct sites on SMO. Both ALLO-1 and ALLO-2 significantly inhibited D477G Smo in TM3-Gli-Luc cells with approximately twofold difference compared to wildtype Smo, whereas vismodegib's effectiveness was reduced by approximately 200 -fold. Saridegib, a derivative of cyclopamine, was generated by modifying the structure of cyclopamine in a screen for improved potency and solubility (Tremblay et al. 2009). Saridegib suppressed mouse medulloblastoma growth and showed less susceptibility to $\mathrm{D} 473 \mathrm{H}$ SMO mutationdriven $\mathrm{HH}$ signaling than vismodegib in a Gliluciferase reporter assay (Lee et al. 2012).

The following set of next-generation $\mathrm{HH}$ antagonists target the GLI transcription factors (Fig. 3). As all known resistance pathways that 
bypass SMO still activate GLI, targeting GLI directly might prove to be the best option as the next level of therapy. Screens of a National Institutes of Health compound library by another group yielded two molecules that block GLI transcriptional activity in a cell-based luciferase screen under a GLI1-dependent reporter. GANT58 and GANT61 were found to block both GLI1 and GLI2 transcriptional activity (Lauth et al. 2007). Both GANTs inhibit HH signaling with an IC50 similar to cyclopamine and suppress tumor growth in human prostate cancer xenografts. GANT61, but not GANT58, blocks GLI1 DNA binding when preincubated in GLI1-expressing cells presumably by altering a posttranslational modification as GANT61 does not directly interfere with GLI1-DNA interaction. GANT61 was also found to inhibit growth of pancreatic tumors and myeloid and lymphocytic leukemia cells (Desch et al. 2010; Fu et al. 2012; Pan et al. 2012). The mechanism of action for both GANT molecules is still under investigation.

In a screen of nearly 123,000 compounds for molecules that block SMO agonist-induced $\mathrm{HH}$ pathway activation in Shh-LIGHT2 cells, scientists identified HPI1 through HPI-4 with IC50 concentrations $<10 \mu \mathrm{M}$ (Hyman et al. 2009). HPI-1 and -4 altered GLI2 processing and GLI1 stability, with the GLI alteration presumably secondary for HPI-4 as that compound disrupted ciliogenesis. HPI-2 and HPI-3 altered GLI2 accumulation in the cilia causing suppression of GLI2 activity. HPI inhibitors have poor solubility in water, thus they are not readily available to antagonize GLI activity under physiological conditions. To improve solubility, HPI-1 was encapsulated into a polymeric nanoparticle that greatly increasing its bioavailability. Systemic treatment with encapsulated HPI-1 suppressed growth of murine medulloblastoma allografts that harbor the Smo D477G mutation rendering these tumors unresponsive to vismodegib (Chenna et al. 2012). In addition, encapsulated HPI-1, in combination with the chemotherapeutic agent gemcitabine, inhibited growth of an orthotopic model of hepatocellular carcinoma better than either treatment alone (Xu et al. 2012).
Independent screens from a group using literature searches and approximately 2400 previously FDA-approved drugs identified arsenical compounds and itraconazole as potential $\mathrm{HH}$ antagonists. Arsenicals were identified from the literature given the similarity of their developmental defects ascribed to their exposure to $\mathrm{HH}$ antagonists (Kim et al. 2010a). Arsenic trioxide (ATO) is a therapeutic agent for acute promyelocytic leukemia and was found to suppress $\mathrm{HH}$ activation in a cell-based Gli reporter assay with an IC50 $<1 \mu \mathrm{M}$. ATO blocks accumulation of Gli2 to primary cilia and Gli2 stability, and potently suppressed growth of medulloblastoma allografts. Itraconazole is an antifungal with mild cholesterol-lowering activity that was shown to inhibit luciferase in a cell-based Gli reporter assay with an IC50 similar to ATO (Kim et al. 2010b). Low-density lipoprotein was shown to mediate itraconazole action on $\mathrm{HH}$ pathway activation and was later shown to act at a site distinct from cyclopamine on SMO. Recently, combination therapy with ATO and itraconazole was shown to inhibit allografted BCC and medulloblastoma tumor growth on mice better than either agent alone (Kim et al. 2013). Both drugs were still effective in the presence of all currently known SMO mutations that block vismodegib or erismodegib, indicating combination therapy may be the most promising of the next-generation $\mathrm{HH}$ antagonists as they are already FDA approved for other conditions. A phase II clinical trial of itraconazole for patients with metastatic castration-resistant prostate cancer showed promising results as the high-dose arm of the study showed modest antitumor activity and an increase in progression-free survival (Antonarakis et al. 2013). In addition, a recently initiated phase I trial will establish if GLI1 or GLI2 expression is decreased in BCC patients treated with ATO (clinical trial \#NCT01791894).

aPKC is an intriguing therapeutic target that was recently identified as a novel activator of GLI1 transcriptional activity (Atwood et al. 2013). aPKC was discovered through a proteomics screen for factors that bound to the GLI scaffold protein MIM. Loss of aPKC, or inhibition with an aPKC-specific peptide inhibitor 
S.X. Atwood et al.

(PSI), suppressed $\mathrm{HH}$ signaling and growth of a mouse BCC cell line with an IC50 similar to cyclopamine at $5 \mu \mathrm{M}$. PSI targeted similar genes as SMO antagonist Sant-1 in BCC cells suggesting aPKC activity drives $\mathrm{HH}$ pathway activity in these cells. aPKC was found to be an $\mathrm{HH}$ target gene that is up-regulated in BCC at both the RNA and protein levels. aPKC phosphorylates GLI1 to promote GLI1 DNA binding and transcriptional activity. aPKC RNA and protein is overexpressed in Sant-1-resistant BCC cells, and PSI treatment was still effective in these resistant cells, whereas molecularly distinct cyclopamine was largely incompetent. aPKC activity is increased in sensitive and resistant human BCCs compared to normal skin, and topical treatment with PSI was tumor specific and resulted in suppression of tumor growth in mouse BCC allografts with no apparent effect on other tissues or nontumorigenic cell lines.

$\mathrm{S} 6 \mathrm{~K} 1$ is another kinase and potential therapeutic target that functions downstream from mTOR to phosphorylate GLI1 and promote activity by suppressing the inhibitory GLI1SUFU interaction (Wang et al. 2012). S6K1 was discovered as a TNF- $\alpha$-specific factor that increased $\mathrm{HH}$ pathway activation in esophageal adenocarcinoma (EAC) cells by promoting Gli1 nuclear localization. Active S6K1 is overexpressed in EAC tissue and inhibition of its upstream activator $\mathrm{mTOR}$ with rapamycin potentiated the effects of vismodegib treatment in EAC cell lines and mouse xenografts. These results provide strong preclinical support for the use of combined therapy to delay growth of SMO antagonist-resistant tumors. Specific S6K1 antagonists, such as PF-4708671, exist but have not been tested for their effect on GLI activation or in S6K1 positive tumors (Pearce et al. 2010).

PI3K signaling, the upstream activator of aPKC and S6K1, was found to be significantly up-regulated in gene expression arrays from erismodegib-resistant mouse medulloblastoma tumors versus sensitive tumors (Buonamici et al. 2010). Combination therapy with erismodegib and NPV-BKM120, a PI3K inhibitor, delayed tumor resistance in allografted mouse medulloblastomas, suggesting that the PI3K pathway can facilitate tumor resistance. S6K1 phosphorylation was completely inhibited with combination therapy, whereas it was only partially inhibited with NPV-BKM120 alone suggesting that $\mathrm{HH}$ pathway inhibition can also influence S6K1 activation. In fact, combination therapy with erismodegib and NVP-BEZ235, a dual PI3K and mTOR inhibitor, suppressed S6K1 phosphorylation and allografted medulloblastoma tumor resistance better than with the combination therapy without mTOR inhibition. Although phase I clinical trials are underway to assess efficacy and tolerability of mTOR inhibitors such as rapamycin (sirolimus) in resistant medulloblastoma patients or renal transplant patients who develop a higher incidence of skin tumors that include BCC (Campbell et al. 2012), trials with combination therapy with SMO antagonists will be particularly enlightening. Other potential targets downstream from PI3K include PDK1, a kinase that activates AKT and aPKC and has several specific small molecule inhibitors (Peifer and Alessi 2008). Targeting the PI3K/AKT/mTOR pathway may compliment SMO inhibition to improve response rates in BCC patients; however, more preclinical work is needed to define this relationship.

\section{CONCLUDING REMARKS}

BCC is a highly prevalent malignancy with most sporadic tumors treatable using traditional therapy that includes both surgical and nonsurgical methods. However, traditional therapies are not as effective in treating multiple BCCs, tumors in cosmetically sensitive areas, or those that become highly invasive or metastatic. As $15 \mathrm{yr}$ of preclinical studies implicated $\mathrm{HH}$ pathway activation for BCC growth, subsequent work toward the development of $\mathrm{HH}$ antagonists proved quite promising. Vismodegib became the first SMO antagonist approved for treating late advanced or metastatic BCC, a drug that significantly increased treatment response compared to traditional methods in BCC patients with high-grade tumors. This first-generation $\mathrm{HH}$ antagonist also revealed the dark side to cancer therapy: resistance through tumor heterogeneity. 
Mutations accumulate as a tumor grows and this can allow resistance to develop, especially if the tumor is under selective pressure. Understanding where these mutations accumulate and what pathways they affect are driving the development of next-generation $\mathrm{HH}$ antagonists to treat drug-resistant BCC. Preliminary evidence suggests the PI3K signaling pathway as a major resistance pathway in BCC, and drugs are under development that target many points of the pathway. Thus, defining escape mechanisms in BCC that bypass SMO blockade will provide vital information for designing rational next-generation therapies and continue our path to eradicate this cancer.

\section{ACKNOWLEDGMENTS}

This work is funded by R01ARO46786 and R01ARO52785. A.E.O. received funds for clinical trials from Genentech/Roche and Novartis.

\section{REFERENCES}

Antonarakis ES, Heath EI, Smith DC, Rathkopf D, Blackford AL, Danila DC, King S, Frost A, Ajiboye AS, Zhao M, et al. 2013. Repurposing Itraconazole as a treatment for advanced prostate cancer: A noncomparative randomized Phase II trial in men with metastatic castration-resistant prostate cancer. Oncologist 18: 163-173.

Atwood SX, Chang ALS, Oro AE. 2012. Hedgehog pathway inhibition and the race against tumor evolution. J Cell Biol 199: 193-197.

Atwood SX, Li M, Lee A, Tang JY, Oro AE. 2013. GLI activation by atypical protein kinase $\mathrm{C} \iota / \lambda$ regulates the growth of basal cell carcinomas. Nature 494: 484-488.

Bristol-Myers Squibb. 2013. Phase 1 multiple ascending dose study of BMS-833923 (XL139) in subjects with solid tumors. U.S. National Institutes of Health, Bethesda, MD (updated May 31, 2013).

Buonamici S, Williams J, Morrissey M, Wang A, Guo R, Vattay A, Hsiao K, Yuan J, Green J, Ospina B, et al. 2010. Interfering with resistance to smoothened antagonists by inhibition of the PI3K pathway in medulloblastoma. Sci Transl Med 2: 51ra70.

Callahan CA, Ofstad T, Horng L, Wang JK, Zhen HH, Coulombe PA, Oro AE. 2004. MIM/BEG4, a Sonic hedgehogresponsive gene that potentiates Gli-dependent transcription. Genes Dev 18: 2724-2729.

Campbell SB, Walker R, Tai SS, Jiang Q, Russ GR. 2012. Randomized controlled trial of sirolimus for renal transplant recipients at high risk for nonmelanoma skin cancer. Am J Transplant 12: 1146-1156.

Chang ALS, Oro AE. 2012. Initial assessment of tumor regrowth after vismodegib in advanced Basal cell carcinoma. Arch Dermatol 148: 1324-1325.
Chen JK, Taipale J, Cooper MK, Beachy PA. 2002. Inhibition of Hedgehog signaling by direct binding of cyclopamine to Smoothened. Genes Dev 16: 2743-2748.

Chenna V, Hu C, Pramanik D, Aftab BT, Karikari C, Campbell NR, Hong S-M, Zhao M, Rudek MA, Khan SR, et al. 2012. A polymeric nanoparticle encapsulated small-molecule inhibitor of Hedgehog signaling (NanoHHI) bypasses secondary mutational resistance to Smoothened antagonists. Mol Cancer Therapeut 11: 165-173.

Chiang C, Litingtung Y, Lee E, Young KE, Corden JL, Westphal H, Beachy PA. 1996. Cyclopia and defective axial patterning in mice lacking Sonic hedgehog gene function. Nature 383: 407-413.

Desch P, Asslaber D, Kern D, Schnidar H, Mangelberger D, Alinger B, Stoecher M, Hofbauer SW, Neureiter D, Tinhofer I, et al. 2010. Inhibition of GLI, but not Smoothened, induces apoptosis in chronic lymphocytic leukemia cells. Oncogene 29: 4885-4895.

Diaz LA, Williams RT, Wu J, Kinde I, Hecht JR, Berlin J, Allen B, Bozic I, Reiter JG, Nowak MA, et al. 2012. The molecular evolution of acquired resistance to targeted EGFR blockade in colorectal cancers. Nature 486: 537540.

Dijkgraaf GJP, Alicke B, Weinmann L, Januario T, West K, Modrusan Z, Burdick D, Goldsmith R, Robarge K, Sutherlin D, et al. 2011. Small molecule inhibition of GDC0449 refractory smoothened mutants and downstream mechanisms of drug resistance. Cancer Res 71: 435-444.

Epstein EH. 2008. Basal cell carcinomas: Attack of the hedgehog. Nat Rev Cancer 8: 743-754.

Epstein EH. 2011. Mommy-Where do tumors come from? J Clin Invest 121: 1681-1683.

Fu J, Rodova M, Roy SK, Sharma J, Singh KP, Srivastava RK, Shankar S. 2012. GANT-61 inhibits pancreatic cancer stem cell growth in vitro and in NOD/SCID/IL2R $\gamma$ null mice xenograft. Cancer Lett 330: 22-32.

Gomez-Ospina N, Chang ALS, Qu K, Oro AE. 2012. Translocation affecting sonic hedgehog genes in basal-cell carcinoma. N Engl J Med 366: 2233-2234.

Grachtchouk M, Pero J, Yang SH, Ermilov AN, Michael LE, Wang A, Wilbert D, Patel RM, Ferris J, Diener J, et al. 2011. Basal cell carcinomas in mice arise from hair follicle stem cells and multiple epithelial progenitor populations. J Clin Invest 121: 1768-1781.

Hassounah NB, Bunch TA, McDermott KM. 2012. Molecular pathways: The role of primary cilia in cancer progression and therapeutics with a focus on Hedgehog signaling. Clin Cancer Res 18: 2429-2435.

Hildebrandt F, Benzing T, Katsanis N. 2011. Ciliopathies. N Engl J Med 364: 1533-1543.

Huangfu D, Liu A, Rakeman AS, Murcia NS, Niswander L, Anderson KV. 2003. Hedgehog signalling in the mouse requires intraflagellar transport proteins. Nature 426: 83-87.

Hui C-C, Angers S. 2011. Gli proteins in development and disease. Annu Rev Cell Dev Biol 27: 513-537.

Humke EW, Dorn KV, Milenkovic L, Scott MP, Rohatgi R. 2010. The output of Hedgehog signaling is controlled by the dynamic association between Suppressor of Fused and the Gli proteins. Genes Dev 24: 670-682. 
S.X. Atwood et al.

Hyman JM, Firestone AJ, Heine VM, Zhao Y, Ocasio CA, Han K, Sun M, Rack PG, Sinha S, Wu JJ, et al. 2009. Small-molecule inhibitors reveal multiple strategies for Hedgehog pathway blockade. Proc Natl Acad Sci 106: 14132-14137.

Kasper M, Jaks V, Are A, Bergström Å, Schwäger A, Barker N, Toftgård R. 2011. Wounding enhances epidermal tumorigenesis by recruiting hair follicle keratinocytes. Proc Natl Acad Sci 108: 4099-4104.

Keady BT, Samtani R, Tobita K, Tsuchya M, San Agustin JT, Follit JA, Jonassen JA, Subramanian R, Lo CW, Pazour GJ. 2012. IFT25 links the signal-dependent movement of Hedgehog components to intraflagellar transport. Dev Cell 22: 940-951.

Keeler RF, Binns W. 1966. Teratogenic compounds of Veratrum californicum (Durand). I. Preparation and characterization of fractions and alkaloids for biologic testing. Can J Biochem 44: 819-828.

Kim J, Lee JJ, Kim J, Gardner D, Beachy PA. 2010a. Arsenic antagonizes the Hedgehog pathway by preventing ciliary accumulation and reducing stability of the Gli2 transcriptional effector. Proc Natl Acad Sci 107: 13432-13437.

Kim J, Tang JY, Gong R, Kim J, Lee JJ, Clemons KV, Chong CR, Chang KS, Fereshteh M, Gardner D, et al. 2010b. Itraconazole, a commonly used antifungal that inhibits Hedgehog pathway activity and cancer growth. Cancer Cell 17: 388-399.

Kim J, Aftab BT, Tang JY, Kim D, Lee AH, Rezaee M, Kim J, Chen B, King EM, Borodovsky A, et al. 2013. Itraconazole and arsenic trioxide inhibit Hedgehog pathway activation and tumor growth associated with acquired resistance to smoothened antagonists. Cancer Cell 23: 23-34.

Lappano R, Maggiolini M. 2011. G protein-coupled receptors: Novel targets for drug discovery in cancer. Nat Rev Drug Discov 10: 47-60.

Lauth M, Bergström Å, Shimokawa T, Toftgård R. 2007. Inhibition of GLI-mediated transcription and tumor cell growth by small-molecule antagonists. Proc Natl Acad Sci 104: 8455-8460.

Lee MJ, Hatton BA, Villavicencio EH, Khanna PC, Friedman SD, Ditzler S, Pullar B, Robison K, White KF, Tunkey C, et al. 2012. Hedgehog pathway inhibitor saridegib (IPI-926) increases lifespan in a mouse medulloblastoma model. Proc Natl Acad Sci 109: 7859-7864.

LoRusso PM, Rudin CM, Reddy JC, Tibes R, Weiss GJ, Borad MJ, Hann CL, Brahmer JR, Chang I, Darbonne WC, et al. 2011. Phase I trial of hedgehog pathway inhibitor vismodegib (GDC-0449) in patients with refractory, locally advanced or metastatic solid tumors. Clin Cancer Res 17: 2502-2511.

Maun HR, Wen X, Lingel A, de Sauvage FJ, Lazarus RA, Scales SJ, Hymowitz SG. 2010. Hedgehog pathway antagonist 5E1 binds hedgehog at the pseudo-active site. J Biol Chem 285: 26570-26580.

Misale S, Yaeger R, Hobor S, Scala E, Janakiraman M, Liska D, Valtorta E, Schiavo R, Buscarino M, Siravegna G, et al. 2012. Emergence of KRAS mutations and acquired resistance to anti-EGFR therapy in colorectal cancer. Nature 486: $532-536$.

Munchhof MJ, Li Q, Shavnya A, Borzillo GV, Boyden TL, Jones CS, LaGreca SD, Martinez-Alsina L, Patel N, Pelletier K, et al. 2012. Discovery of PF-04449913, a potent and orally bioavailable inhibitor of Smoothened. ACS Med Chem Lett 3: 106-111.

Nilsson M, Undén AB, Krause D, Malmqwist U, Raza K, Zaphiropoulos PG, Toftgard R. 2000. Induction of basal cell carcinomas and trichoepitheliomas in mice overexpressing GLI-1. Proc Natl Acad Sci 97: 3438-3443.

Oro AE, Higgins K. 2003. Hair cycle regulation of Hedgehog signal reception. Dev Biol 255: 238-248.

Oro AE, Higgins KM, Hu Z, Bonifas JM, Epstein EH, Scott MP. 1997. Basal cell carcinomas in mice overexpressing sonic hedgehog. Science 276: 817-821.

Pan D, Li Y, Li Z, Wang Y, Wang P, Liang Y. 2012. Gli inhibitor GANT61 causes apoptosis in myeloid leukemia cells and acts in synergy with rapamycin. Leuk Res 36: $742-748$.

Pearce LR, Alton GR, Richter DT, Kath JC, Lingardo L, Chapman J, Hwang C, Alessi DR. 2010. Characterization of PF-4708671, a novel and highly specific inhibitor of p70 ribosomal S6 kinase (S6K1). Biochem J 431: $245-$ 255.

Peifer C, Alessi DR. 2008. Small-molecule inhibitors of PDK1. ChemMedChem 3: 1810-1838.

Riobó NA, Lu K, Ai X, Haines GM, Emerson CP. 2006. Phosphoinositide 3-kinase and Akt are essential for Sonic Hedgehog signaling. Proc Natl Acad Sci 103: 4505-4510.

Robarge KD, Brunton SA, Castanedo GM, Cui Y, Dina MS, Goldsmith R, Gould SE, Guichert O, Gunzner JL, Halladay J, et al. 2009. GDC-0449-a potent inhibitor of the hedgehog pathway. Bioorg Med Chem Lett 19: $5576-$ 5581.

Rubin AI, Chen EH, Ratner D. 2005. Basal-cell carcinoma. $N$ Engl J Med 353: 2262-2269.

Sekulic A, Migden MR, Oro AE, Dirix L, Lewis KD, Hainsworth JD, Solomon JA, Yoo S, Arron ST, Friedlander PA, et al. 2012. Efficacy and safety of vismodegib in advanced basal-cell carcinoma. N Engl J Med 366: 2171-2179.

Skvara H, Kalthoff F, Meingassner JG, Wolff-Winiski B, Aschauer H, Kelleher JF, Wu X, Pan S, Mickel L, Schuster C, et al. 2011. Topical treatment of Basal cell carcinomas in nevoid Basal cell carcinoma syndrome with a smoothened inhibitor. J Invest Dermatol 131: 1735-1744.

Tang JY, Marghoob AA. 2011. Emerging treatments and signaling pathway inhibitors. Semin Cutan Med Surg 30: S14-S18.

Tang T, Tang JY, Li D, Reich M, Callahan CA, Fu L, Yauch RL, Wang F, Kotkow K, Chang KS, et al. 2011. Targeting superficial or nodular Basal cell carcinoma with topically formulated small molecule inhibitor of smoothened. Clin Cancer Res 17: 3378-3387.

Tang JY, Mackay-Wiggan JM, Aszterbaum M, Yauch RL, Lindgren J, Chang K, Coppola C, Chanana AM, Marji J, Bickers DR, et al. 2012. Inhibiting the hedgehog pathway in patients with the basal-cell nevus syndrome. $N$ Engl J Med 366: 2180-2188.

Tao H, Jin Q, Koo D-I, Liao X, Englund NP, Wang Y, Ramamurthy A, Schultz PG, Dorsch M, Kelleher J, et al. 2011 Small molecule antagonists in distinct binding modes inhibit drug-resistant mutant of smoothened. Chem Biol 18: $432-437$.

Tremblay MR, Lescarbeau A, Grogan MJ, Tan E, Lin G, Austad BC, Yu L-C, Behnke ML, Nair SJ, Hagel M, et 
al. 2009. Discovery of a potent and orally active hedgehog pathway antagonist (IPI-926). J Med Chem 52: 44004418.

Tukachinsky H, Lopez LV, Salic A. 2010. A mechanism for vertebrate Hedgehog signaling: Recruitment to cilia and dissociation of SuFu-Gli protein complexes. J Cell Biol 191: 415-428.

Varjosalo M, Taipale J. 2008. Hedgehog: Functions and mechanisms. Genes Dev 22: 2454-2472.

Von Hoff DD, LoRusso PM, Rudin CM, Reddy JC, Yauch RL, Tibes R, Weiss GJ, Borad MJ, Hann CL, Brahmer JR, et al. 2009. Inhibition of the hedgehog pathway in advanced basal-cell carcinoma. N Engl J Med 361: 11641172.

Wang GY, Wang J, Mancianti M-L, Epstein EH. 2011. Basal cell carcinomas arise from hair follicle stem cells in Ptch $1^{+/-}$mice. Cancer Cell 19: 114-124.

Wang Y, Ding Q, Yen C-J, Xia W, Izzo JG, Lang J-Y, Li C-W, Hsu JL, Miller SA, Wang X, et al. 2012. The crosstalk of mTOR/S6K1 and Hedgehog pathways. Cancer Cell 21: 374-387.
Wong SY, Reiter JF. 2011. From the cover: Wounding mobilizes hair follicle stem cells to form tumors. Proc Natl Acad Sci 108: 4093-4098.

Wong SY, Seol AD, So P-L, Ermilov AN, Bichakjian CK, Epstein EH, Dlugosz AA, Reiter JF. 2009. Primary cilia can both mediate and suppress Hedgehog pathway-dependent tumorigenesis. Nat Med 15: 1055-1061.

Xu Y, Chenna V, Hu C, Sun H-X, Khan M, Bai H, Yang X-R, Zhu Q-F, Sun Y-F, Maitra A, et al. 2012. Polymeric nanoparticle-encapsulated hedgehog pathway inhibitor HPI-1 (NanoHHI) inhibits systemic metastases in an orthotopic model of human hepatocellular carcinoma. Clin Cancer Res 18: 1291-1302.

Yauch RL, Dijkgraaf GJP, Alicke B, Januario T, Ahn CP, Holcomb T, Pujara K, Stinson J, Callahan CA, Tang T, et al. 2009. Smoothened mutation confers resistance to a Hedgehog pathway inhibitor in medulloblastoma. Science 326: $572-574$.

Youssef KK, Van Keymeulen A, Lapouge G, Beck B, Michaux C, Achouri Y, Sotiropoulou PA, Blanpain C. 2010. Identification of the cell lineage at the origin of basal cell carcinoma. Nat Cell Biol 12: 299-305. 


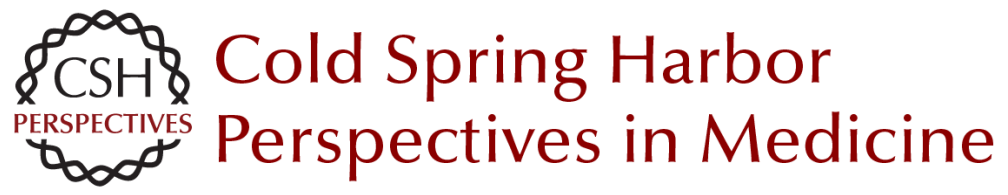

\section{Advanced Treatment for Basal Cell Carcinomas}

Scott X. Atwood, Ramon J. Whitson and Anthony E. Oro

Cold Spring Harb Perspect Med 2014; doi: 10.1101/cshperspect.a013581

Subject Collection The Skin and Its Diseases

Melanoma: Clinical Features and Genomic Insights

Elena B. Hawryluk and Hensin Tsao

Wound Healing and Skin Regeneration

Makoto Takeo, Wendy Lee and Mayumi Ito

The Dermal Papilla: An Instructive Niche for

Epithelial Stem and Progenitor Cells in

Development and Regeneration of the Hair Follicle Bruce A. Morgan

Immunology and Skin in Health and Disease Jillian M. Richmond and John E. Harris

Desmosomes: Regulators of Cellular Signaling and Adhesion in Epidermal Health and Disease Jodi L. Johnson, Nicole A. Najor and Kathleen J. Green

Markers of Epidermal Stem Cell Subpopulations in Adult Mammalian Skin Kai Kretzschmar and Fiona M. Watt

Psoriasis

Paola Di Meglio, Federica Villanova and Frank O. Nestle

Cell Therapy in Dermatology Gabriela Petrof, Alya Abdul-Wahab and John A. McGrath
Modeling Cutaneous Squamous Carcinoma

Development in the Mouse

Phillips Y. Huang and Allan Balmain

Natural and Sun-Induced Aging of Human Skin Laure Rittié and Gary J. Fisher

Advanced Treatment for Basal Cell Carcinomas Scott X. Atwood, Ramon J. Whitson and Anthony E. Oro

Epidermal Polarity Genes in Health and Disease Frederik Tellkamp, Susanne Vorhagen and Carien M. Niessen

Induced Pluripotent Stem Cells in Dermatology:

Potentials, Advances, and Limitations Ganna Bilousova and Dennis R. Roop

The Genetics of Human Skin Disease Gina M. DeStefano and Angela M. Christiano

p53/p63/p73 in the Epidermis in Health and Disease

Vladimir A. Botchkarev and Elsa R. Flores

Diversification and Specialization of Touch

Receptors in Skin

David M. Owens and Ellen A. Lumpkin

For additional articles in this collection, see http://perspectivesinmedicine.cshlp.org/cgi/collection/ 